\title{
Critical Appraisal of Minimally Invasive Keyhole Surgery for Intracranial Meningioma
}

Jai Deep Thakur

University of South Alabama

Regin Jay Mallari

Pacific Neuroscience Institute

Alex Corlin

Pacific Neuroscience Institute

Samantha Yawitz

Pacific Neuroscience Institute

Amalia Eisenberg

Pacific Neuroscience Institute

John Rhee

Pacific Neuroscience Institute

Walavan Sivakumar

Pacific Neuroscience Institute

Howard Krauss

Pacific Neuroscience Institute

Neil Martin

Pacific Neuroscience Institute

Chester Griffiths

Pacific Neuroscience Institute

Garni Barkhoudarian

Pacific Neuroscience Institute

Daniel F. Kelly ( $\nabla$ kellyd@jwci.org )

Pacific Neuroscience Institute https://orcid.org/0000-0002-8358-056X

\section{Research Article}

Keywords: meningioma, intracranial, endoscopy, keyhole, minimally invasive surgery, endonasal, supraorbital, retromastoid, cerebrospinal fluid leak, complication, length of stay

Posted Date: January 3rd, 2022

DOI: https://doi.org/10.21203/rs.3.rs-1208627/v1

License: (c) (i) This work is licensed under a Creative Commons Attribution 4.0 International License. Read Full License 


\section{Abstract \\ Purpose}

Minimally invasive meningioma removal through transcranial and endoscopic endonasal keyhole routes remain controversial. Herein we detail results of keyhole meningioma removal defined as use of a minimally invasive "retractorless" approach for which a traditional larger approach is often used instead.

\section{Methods}

Retrospective analysis from 2008-2021 of consecutive patients undergoing keyhole meningioma removal through one of six approaches: extent of resection, complications, endoscopy use, MRI FLAIR/T2 changes. Surgical goal was maximal safe removal including conservative(subtotal) removal for some invasive locations.

\section{Results}

Of 329 patients, keyhole approaches were utilized in 193(59\%) patients (mean age 59 $\pm 13 ; 30(15.5 \%)$ prior surgery) who underwent 213 operations; 205(96\%) were skull base location. Approaches included: endoscopic endonasal(n=74,35\%), supraorbital( $n=73,34 \%)$, retromastoid $(n=38,18 \%)$, mini-pterional $(n=20,9 \%)$, suboccipital $(n=4,2 \%)$, and contralateral transfalcine(n=4,2\%). Primary outcomes: Gross total/near total(>90\%) resection: $125(59 \%)$; (5\% for petroclival, cavernous sinus/Meckel's cave, spheno-cavernous locations vs $77 \%$ other locations). Complications included: permanent neurological worsening12(6\%); CSF leak 2(1\%); meningitis 2(1\%); no patients sustained DVT, PE, MI, or 30-day mortality. Median LOS was 3 days with 94\% discharged home and $96 \%$ with favorable 90 -day KPS. Secondary outcomes: Small persistent FLAIR/T2 changes: 11(5.2\%) patients. Endoscopy use: 87/139(63\%) of craniotomies, facilitating additional tumor removal in 55\%. Tumor progression was observed in $26(13 \%)$ patients(mean follow-up $42 \pm 36$ months).

\section{Conclusion}

This analysis suggests keyhole meningioma removal can be associated with reasonable resection rates, low complication rates, short hospitalizations and high 90-day performance scores. Subtotal removal may be appropriate for invasive/adherent meningiomas to avoid complications. With careful patient selection and requisite experience, these approaches may be considered alternatives to traditional approaches.

\section{Introduction}

Meningiomas are the most common primary brain tumor with almost 35,000 patients being diagnosed annually in the US $^{1}$, and although $85-90 \%$ are benign (WHO Grade 1), they frequently encase or become adherent to arteries, veins and cranial nerves, and have a propensity to invade multiple skull base compartments. While surgery remains first-line treatment for meningiomas, the approach used and aggressiveness of removal is highly location-dependent and influenced by other factors such as tumor invasiveness, prior treatments and surgeons' philosophy. Innovative skull base surgery approaches developed in the early 1990s generally employed large incisions, extensive bone removal and promoted maximal tumor removal as the primary goal. However, results from multiple series using these approaches indicate that overly aggressive tumor removal can be associated with relatively high rates of permanent cranial nerve deficits and other neurological complications ${ }^{2-5}$. Furthermore, stereotactic radiosurgery and radiotherapy (SRS or SRT) have long-term control rates of $90 \%$ or higher for most recurrent or progressive WHO grade I meningiomas, and some primarily treated cavernous sinus (CS) meningiomas ${ }^{6-9}$. Thus, over time, restoring or maintaining neurological function 
and quality of life have gained greater priority and the dictum of maximal safe tumor remova/ has gained wider acceptance $2,10-13$.

Minimally invasive surgical (MIS) techniques have been increasingly applied across multiple surgical subspecialties often with the aid of endoscopy ${ }^{14,15}$. Although the concept of minimally invasive brain tumor removal has been promoted for decades, it has remained controversial and not widely practiced. The term "keyhole surgery" was introduced 50 years ago by Donald Wilson in his 1971 technical note, "Limited exposure in cerebral surgery"16. Since the 1990s, the keyhole concept has been refined by application of modern micro-neurosurgical techniques and technology ${ }^{17,18}$. In the last 20 years, the endoscopic endonasal approach has evolved into an accepted and commonly used minimally invasive route for many midline skull base pathologies, given its ability to facilitate tumor removal without brain retraction ${ }^{19-23}$.

For almost 15 years, we have used several minimally invasive approaches for brain tumors, particularly for skull base and parafalcine meningiomas that eliminate the need for fixed brain retraction by relying on gravity assistance and endoscopic visualization ${ }^{24-32}$. Herein we report detailed outcomes and two illustrative videos of our use of these MIS approaches including extent of resection, the value of endoscopy for tumor removal, complications, LOS, and 90-day performance status in a large cohort of patients with meningioma treated over 13 years. By measuring acute postoperative MRI changes, we also demonstrate that these "retractorless" approaches can be performed with minimal brain impact and manipulation. Except for our recent report on elderly meningioma patients and that by Burks et al, to our knowledge, there are no prior studies with over 40 patients treated with a minimally invasive keyhole paradigm for all intracranial meningiomas 26,33 .

\section{Methods}

\section{Patient population \& data collection}

After institutional review board approval (IRB\# JWCI-19-1101), all patients at Saint John's Health Center, Santa Monica, CA, between January 2008 and January 2021 who underwent surgical removal of an intracranial meningioma were identified. Patient consent was not necessary as data was deidentified. All operations were performed by one of two neurosurgeons (DK, GB) and endonasal operations were performed with otolaryngology collaboration (CG). Data collection included prior treatments, tumor histopathology, size and location on MRI, endoscope usage, extent of resection, complications, length of stay, disposition, readmissions and long-term tumor control.

MIS "keyhole" definition and approach selection: Keyhole approaches are defined as: the use of a minimally invasive approach for a given tumor in which a traditional larger approach may be used instead. These six approaches include the endoscopic endonasal, supraorbital, mini-pterional, retromastoid, suboccipital tentorial and transfalcine routes (Figure $1 \mathrm{~A}$ \& 1B, supplemental GIF, Supplemental Table 1). Non-keyhole approaches include convexity craniotomies, pterional, and bifrontal craniotomies, orbito-zygomatic and other traditional skull base approaches, and far-lateral approaches. Table 1 describes the strategy for applying these 6 keyhole approaches; two videos provide 6 case examples. During the study period, traditional open skull base craniotomies were rarely used. 
Table 1

Surgical Decision Making for Keyhole Meningioma Removal

\begin{tabular}{|c|c|c|}
\hline $\begin{array}{l}\text { Meningioma } \\
\text { Location }\end{array}$ & $\begin{array}{l}\text { Factors for Surgical } \\
\text { Decision Making }\end{array}$ & Approach Selection \\
\hline $\begin{array}{l}\text { Olfactory } \\
\text { Groove/ }\end{array}$ & Olfaction preservation & Supraorbital \\
\hline \multicolumn{3}{|l|}{ Anterior Planum } \\
\hline \multirow{5}{*}{$\begin{array}{l}\text { Posterior } \\
\text { Planum/ } \\
\text { Tuberculum Sella }\end{array}$} & $\begin{array}{l}\text { 1. Proportion of tumor } \\
\text { above the planum }\end{array}$ & \multirow{5}{*}{$\begin{array}{l}\text { Majority of tumor below planum, deep sella, steep (acute) } \\
\text { tuberculum angle, minimal lateral extension, small size (under } 3 \\
\mathrm{~cm} \text { ): Favor Endonasal } \\
\text { Medial optic canal invasion: Favor Endonasal } \\
\text { Majority of tumor above planum, shallow sella, broad tuberculum } \\
\text { angle, significant lateral extension, lack of medial optic canal } \\
\text { invasion, larger size (over } 3 \mathrm{~cm} \text { ): Favor Supraorbital }\end{array}$} \\
\hline & & \\
\hline & 3. Optic canal Invasion & \\
\hline & $\begin{array}{l}\text { 4. Extent of tumor } \\
\text { extension lateral to } \\
\text { supraclinoid ICA }\end{array}$ & \\
\hline & 5. Maximal tumor diameter & \\
\hline Clinoidal & Extension into middle fossa & $\begin{array}{l}\text { Predominantly above the lesser wing: favor Supraorbital } \\
\text { Predominantly within the middle fossa: favor Mini-pterional }\end{array}$ \\
\hline Sphenoid Wing & $\begin{array}{l}\text { Angle of Attack with } \\
\text { respect to the Optic Chiasm } \\
\text { and Supraclinoid Carotid }\end{array}$ & Mini-pterional \\
\hline & $\begin{array}{l}\text { Angle of attack with respect } \\
\text { to the optic chiasm and }\end{array}$ & Mini-pterional \pm orbitotomy \\
\hline $\begin{array}{l}\text { Spheno } \\
\text { Cavernous }\end{array}$ & supraclinoid carotid artery & \\
\hline $\begin{array}{l}\text { Cavernous } \\
\text { Sinus/ Meckel's } \\
\text { Cave, Spheno- } \\
\text { cavernous }\end{array}$ & $\begin{array}{l}\text { Surgical goal of } \\
\text { decompression }\end{array}$ & Endonasal \\
\hline \multirow{2}{*}{$\begin{array}{l}\text { Petroclival/ CP } \\
\text { Angle/ Foramen } \\
\text { Magnum }\end{array}$} & \multirow[t]{2}{*}{$\begin{array}{l}\text { Clival and CP Angle } \\
\text { component }\end{array}$} & $\begin{array}{l}\text { If substantial petrous and posterior CP angle component } \\
\text { posterolateral to CN VI: Favor Retromastoid }\end{array}$ \\
\hline & & $\begin{array}{l}\text { If substantial clival component more anterior: Favor Endonasal } \pm \\
\text { Retromastoid }\end{array}$ \\
\hline Tentorial & Proximity to convexity & $\begin{array}{l}\text { If away from convexity - Suboccipital sitting gravity-assisted } \\
\text { endoscopic-assisted or fully endoscopic }\end{array}$ \\
\hline Falx & $\begin{array}{l}\text { Abutting primary motor or } \\
\text { sensory cortex with } \\
\text { overlying ipsilateral cortex }\end{array}$ & Contralateral gravity-assisted trans-tentorial endoscopic \\
\hline
\end{tabular}

Surgical goals, preparation and technique: A goal of maximal safe tumor removal was applied across all tumor locations. However, subtotal removal was typically the goal for three meningioma subtypes given their invasive nature and tendency to encase neurovascular structures: petroclival, CS/Meckel's cave, and spheno-cavernous locations, as well as some meningiomas with prior surgery and/or radiotherapy ${ }^{28}$. Residual meningioma was deliberately left along neurovascular structures if too adherent or left in the skull base bone if deemed too infiltrative. Four patients had planned staged approaches for large meningiomas (maximal diameter $>6 \mathrm{~cm}$ : endonasal debulking combined with a pterional, minipterional or retromastoid approach. 
Total intravenous anesthesia (TIVA) was used to promote rapid emergence from anesthesia ${ }^{31}$. Preoperative tumor embolization was not used. Lumbar drains for CSF diversion were used infrequently and only early in the series. As recently described and highlighted in Video 1 , all endonasal cases were performed fully endoscopically using a $0^{\circ} 4$-mm rigid endoscope initially; $30^{\circ}$ and $45^{\circ}$ endoscopes (Karl Storz-America, El Segundo, CA), are used at various stages of the procedure ${ }^{28,32}$. A pedicled nasoseptal flap (or middle turbinate flap) is harvested in cases of tuberculum and planum meningiomas but not for all CS/Meckel cave meningiomas, depending upon CSF leak grade $28,29,32$.

Except for the fully endoscopic sitting suboccipital approach, all transcranial keyhole craniotomies are performed initially with the microscope and then with endoscopy as needed for illuminating areas poorly seen with the microscope, and for endoscopic tumor resection. Endoscopy is typically performed with an assistant driving the endoscope. Patient positioning is critical to optimize gravity-assisted exposure and for endoscopy. Our use of the supraorbital and minipterional approaches have been well-described $30,32,34$. The retromastoid approach is performed with the patient supine or lateral position, utilizing a short linear or curvilinear incision with approximately $2 \times 3 \mathrm{~cm}$ craniotomy ${ }^{33}$. The suboccipital approach is performed in the sitting or lateral position typically using an approximate $2 \times 2 \mathrm{~cm}$ craniotomy for tentorial meningiomas. As previously described (and highlighted in Video 2), the gravity-assisted transfalcine approach is performed specifically for parafalcine meningiomas that have a rind of edematous overlying eloquent cortex at risk from an ipsilateral approach ${ }^{24}$. The patient is placed in lateral position with tumor side up and inclined in reverse Trendelenburg position with the vertex at 30-45 degrees ${ }^{24}$, allowing for gravity-retraction and access from the unaffected contralateral side.

Outcome and statistical analysis: Primary outcomes included extent of tumor resection, complications, hospital LOS, reoperations and readmissions within 90 days, 30-day mortality, KPS, and cranial (CN) outcomes. A favorable KPS at $\geq 90$ days follow-up was defined as improved or unchanged from preoperative KPS. As previously published, resection rates were categorized as: gross total resection (GTR), near total resection (NTR $\geq 90 \%$ tumor resection), or subtotal resection (< $90 \%)^{26,32}$. Simpson resection classification was not assessed given that most patients had invasive skull base meningiomas in which complete tumor resection and removal of involved bone and dura is typically not feasible $26,32,35$.

Three secondary outcomes were included: 1) To quantify approach-related trauma of tumor removal, post-operative day \#1 or 2 MRIs were independently assessed by a neuroradiologist (JR) for new FLAIR/T2 signal changes in the peritumoral and surgical approach areas ${ }^{32}$. New FLAIR/T2 change in the axial plane around the resection area or approach trajectory was quantified by maximal diameters. Persistence or resolution was documented on 3-month postoperative MRI. 2) For transcranial operations, as previously published, the utility of endoscopic visualization was determined by if endoscopy facilitated additional tumor removal ${ }^{30,32} 3$ ) Tumor progression or recurrence based on sequential MRIs and need for additional treatment (repeat surgery and/or radiotherapy) was assessed for each patient.

The statistical comparison of the mean in the data amongst different groups was performed using ANOVA and independent Student's t-test. Univariate analysis was done using Chi-square or Fisher's exact test when applicable. Binomial multivariate analysis was done using logistic regression analysis and p-values less than 0.05 were considered statistically significant. Tumor control data for testing binomial variables were plotted using Cox Regression and KaplanMeier analysis.

\section{Results}

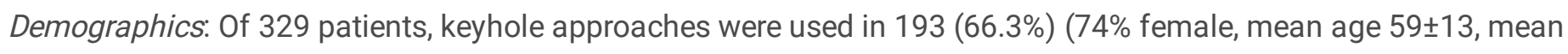
follow up 42 \pm 36 months; WHO Grade I: 173/193(89.6\%), Grade II: 19/193(9.8\%), Grade III: 1/193(0.6\%)); 32(9.7\%) had prior radiation. The 213 keyhole approaches included 205 (96\%) for skull base location and 47(22\%) were in patients with prior surgery. Approaches were endonasal $(n=74)$, supraorbital $(n=73)$, retromastoid $(n=38)$, mini-pterional $(n=20)$, sitting 
suboccipital $(n=4)$, and contralateral gravity-assisted transfalcine $(n=4)$ (Table 2). Four patients had planned staged approaches for large meningiomas (endonasal combined with a pterional, mini-pterional or retromastoid approach). Lumbar drains were used in 5/74(7\%) endonasal cases all prior to 2013, and 1/139 (0.7\%) transcranial approach in 2017.

Table 2

Meningioma Characteristics, Resection Rates \& Surgical Parameters for 213 Keyhole Operations

\begin{tabular}{|c|c|c|c|c|c|c|c|}
\hline & $\begin{array}{l}\text { Endonasal } \\
(n=74)\end{array}$ & $\begin{array}{l}\text { Supraorbital } \\
(n=73)\end{array}$ & $\begin{array}{l}\text { Mini- } \\
\text { pterional } \\
(n=20)\end{array}$ & $\begin{array}{l}\text { Retromastoid } \\
(n=38)\end{array}$ & $\begin{array}{l}\text { Suboccipital } \\
(n=4)\end{array}$ & $\begin{array}{l}\text { Transfalcine } \\
(n=4)\end{array}$ & $\begin{array}{l}\text { Total } \\
(n=213)\end{array}$ \\
\hline GTR & $17(23 \%)$ & $34(46.6 \%)$ & $\begin{array}{l}10 \\
(50 \%)\end{array}$ & $19(50 \%)$ & $2(50 \%)$ & $3(75 \%)$ & $\begin{array}{l}85 \\
(40 \%)\end{array}$ \\
\hline GTR/NTR & $\begin{array}{l}22 \\
(29.7 \%)\end{array}$ & $54(74 \%)$ & $\begin{array}{l}14 \\
(70 \%)\end{array}$ & $28(73.7 \%)$ & 3 (75\%) & $4(100 \%)$ & $\begin{array}{l}125 \\
(58.7 \%)\end{array}$ \\
\hline Redo Surgery & $\begin{array}{l}24 \\
(32.4 \%)\end{array}$ & $16(21.9 \%)$ & $3(15 \%)$ & $3(7.9 \%)$ & $1(25 \%)$ & 0 & $\begin{array}{l}47 \\
(22.1 \%)\end{array}$ \\
\hline $\begin{array}{l}\text { Invasion to } \\
\text { CS/MC/Orbit } \\
\text { /ITF }\end{array}$ & $40(54 \%)$ & 15 (21\%) & $\begin{array}{l}10 \\
(50 \%)\end{array}$ & $9(24 \%)$ & 0 & 0 & $\begin{array}{l}74 \\
(35 \%)\end{array}$ \\
\hline $\begin{array}{l}\text { Median Skull } \\
\text { Base } \\
\text { Compartments } \\
\text { Occupied }\end{array}$ & 2 & 2 & 2 & 2 & 1 & 1 & 2 \\
\hline $\begin{array}{l}\text { Mean Max } \\
\text { Tumor } \\
\text { Diameter }(\mathrm{mm})\end{array}$ & $\begin{array}{l}29.1 \pm \\
13.2\end{array}$ & $28.5 \pm 13.0$ & $\begin{array}{l}29.7 \pm \\
14.1\end{array}$ & $32.1 \pm 13.5$ & $26.5 \pm 12.5$ & $40.0 \pm 21.2$ & $\begin{array}{l}29.7 \pm \\
13.4\end{array}$ \\
\hline $\begin{array}{l}\text { Use of } \\
\text { Endoscopy }\end{array}$ & $74(100 \%)$ & $\begin{array}{l}54 / 73 \\
(74 \%)\end{array}$ & $\begin{array}{l}5 / 20 \\
(25 \%)\end{array}$ & 21/38 (55\%) & $3 / 4(75 \%)$ & $4 / 4(100 \%)$ & $\begin{array}{l}161 / 213 \\
(76 \%)\end{array}$ \\
\hline \multirow{3}{*}{$\begin{array}{l}\text { New/Worsened } \\
\text { FLAIR/T2 } \\
\text { Changes } \\
\text { (mean diam, } \\
\text { mm) }\end{array}$} & $2 / 74$ & $11 / 73$ & $4 / 20$ & $18 / 48$ & $1 / 4$ & $0 / 4$ & $36 / 213$ \\
\hline & $2.7 \%$ & $15.1 \%$ & $20.0 \%$ & $37.5 \%$ & $25 \%$ & 0 & $(16.9 \%)$ \\
\hline & $(2.5 \mathrm{~mm})$ & $(6.9 \mathrm{~mm})$ & $\begin{array}{l}(9.5 \\
\mathrm{mm})\end{array}$ & $(8.1 \mathrm{~mm})$ & $(11 \mathrm{~mm})$ & (NA) & $\begin{array}{l}(7.67 \\
\mathrm{mm})\end{array}$ \\
\hline $\begin{array}{l}\text { Persistent } \\
\text { FLAIR Changes } \\
\text { at } 3 \text { months or } \\
\text { more postop }\end{array}$ & $\begin{array}{l}1 / 74 \\
(1.4 \%)\end{array}$ & 2/73 (2.7\%) & $\begin{array}{l}2 / 20 \\
(10 \%)\end{array}$ & $6 / 48(12.5 \%)$ & 0 & 0 & $\begin{array}{l}11 / 213 \\
(5.2 \%)\end{array}$ \\
\hline Median LOS & 3 & 3 & 2 & 2 & 3 & 2 & 3 \\
\hline
\end{tabular}

\section{PRIMARY OUTCOMES:}

Resection rates by approach and tumor location: As shown in Tables 2 and 3, GTR was achieved in 85(40\%) operations while GTR/NTR (>90\% resection) was achieved in 125(59\%) operations. By meningioma location, GTR/NTR rates were highest for frontal fossa, parafalcine tentorial, olfactory groove and planum meningiomas ( $\mathrm{N}=158$, range $84-100 \%)$, and lowest for spheno-cavernous, CS/Meckel's cave, petroclival ( $N=55$, range 5-6\%) (Table 3). Excluding petroclival, CS/MC and spheno-cavernous location, GTR/NTR was achieved in 114/136 (84\%) in first-time operations. Dense adherence to neurovascular structures was associated with $36 \%$ GTR/NTR versus $100 \%$, without dense adhesions. $(p<0.001)$.

(Supplemental Table 2). All patients with STR/NTR had at least one risk factor (prior surgery, radiotherapy, invasion cavernous sinus/Meckel's cave/infratemporal fossa/orbit). 
Table 3

Resection Rates in 213 Keyhole Approaches by Meningioma Location, Invasiveness \& Use of Endoscopy

\begin{tabular}{|c|c|c|c|c|c|}
\hline Tumor Location $(\mathrm{N})$ & $\begin{array}{l}\text { Overall } \\
\text { GTR/NTR } \\
(\mathrm{n}=\mathbf{2 1 3})\end{array}$ & $\begin{array}{l}\text { First-time Surgery } \\
\text { GTR/NTR } \\
(n=166)\end{array}$ & $\begin{array}{l}\text { Overall } \\
\text { GTR } \\
(n=213)\end{array}$ & $\begin{array}{l}\text { First-time Surgery } \\
\text { GTR }(n=166)\end{array}$ & $\begin{array}{l}\text { Use of } \\
\text { Endoscopy } \\
(n=213)\end{array}$ \\
\hline Frontal Fossa (8) & $8(100 \%)$ & $8 / 8(100 \%)$ & $8(100 \%)$ & $8 / 8(100 \%)$ & 7 (88\%) \\
\hline Parafalcine (4) & $4(100 \%)$ & $4 / 4(100 \%)$ & $3(75 \%)$ & $3 / 4(75 \%)$ & $4(100 \%)$ \\
\hline Tentorial (18) & $17(94 \%)$ & $17 / 17(100 \%)$ & $13(72 \%)$ & $13 / 17(77 \%)$ & $12(67 \%)$ \\
\hline Olfactory Groove (14) & $12(86 \%)$ & $11 / 12(92 \%)$ & $9(64 \%)$ & $8 / 12(67 \%)$ & $14(100 \%)$ \\
\hline Planum Sphenoidale (12) & $10(84 \%)$ & $8 / 10(80 \%)$ & $4(33 \%)$ & $3 / 10(30 \%)$ & $9(75 \%)$ \\
\hline Clinoidal (19) & $14(74 \%)$ & $13 / 15(87 \%)$ & $8(42 \%)$ & $8 / 15(53 \%)$ & $12(63 \%)$ \\
\hline Tuberculum Sellae (39) & $28(72 \%)$ & 26/31 (84\%) & $22(56 \%)$ & 22/31 (71\%) & $33(85 \%)$ \\
\hline Cerebellopontine Angle (23) & $16(70 \%)$ & $14 / 21(67 \%)$ & $9(39 \%)$ & $8 / 21(38 \%)$ & $14(61 \%)$ \\
\hline Sphenoid Wing (16) & $\begin{array}{l}10 \\
(62.5 \%)\end{array}$ & $10 / 15(67 \%)$ & $7(44 \%)$ & $7 / 15(47 \%)$ & $7(44 \%)$ \\
\hline Spheno-orbital (5) & $3(60 \%)$ & $3 / 3(100 \%)$ & $1(20 \%)$ & 1/3 (33\%) & $1(20 \%)$ \\
\hline Total & $\begin{array}{l}122 / 158 \\
=77 \%\end{array}$ & $114 / 136=84 \%$ & $\begin{array}{l}84 / 158 \\
=53 \%\end{array}$ & $81 / 136=60 \%$ & \\
\hline Petroclival (17)* & $1(6 \%)$ & $1 / 9(11 \%)$ & $0(0 \%)$ & $0 / 9(0 \%)$ & $14(82 \%)$ \\
\hline CS/MC (19)* & $1(5 \%)$ & $0 / 10(0 \%)$ & $0(0 \%)$ & $0 / 10(0 \%)$ & $18(95 \%)$ \\
\hline Spheno-cavernous (19)* & $1(5 \%)$ & $1 / 11(10 \%)$ & $1(5 \%)$ & $1 / 11(10 \%)$ & $16(84 \%)$ \\
\hline Total & $3 / 55=5 \%$ & $2 / 30=7 \%$ & $1 / 55=2 \%$ & $1 / 30=3 \%$ & \\
\hline TOTAL & $\begin{array}{l}125 \\
(59 \%)\end{array}$ & $116(70 \%)$ & $85(40 \%)$ & $82(49 \%)$ & $161(76 \%)$ \\
\hline \multicolumn{6}{|l|}{$\begin{array}{l}\text { Dense adherence to critical } \\
\text { neurovascular structures }\end{array}$} \\
\hline Yes $(N=138)$ & \multicolumn{2}{|l|}{$50(36 \%)$} & \multicolumn{3}{|l|}{$20(15 \%)$} \\
\hline No $(N=75)$ & \multicolumn{2}{|l|}{$\begin{array}{l}75 \\
(100 \%)\end{array}$} & \multicolumn{3}{|l|}{$65(87 \%)$} \\
\hline p-value & \multicolumn{2}{|l|}{$p<0.001$} & \multicolumn{3}{|l|}{$p<0.001$} \\
\hline \multicolumn{6}{|c|}{ Abbreviations: GTR: gross total resection, NTR: near total resection, CS: cavernous Sinus, MC: Meckel's cave. } \\
\hline \multicolumn{6}{|c|}{$\begin{array}{l}\text { *These } 3 \text { locations represent a subset of } 55 \text { invasive skull base meningiomas in which conservative (subtotal) } \\
\text { removal was the surgical goal. Of these } 55 \text { cases; } 7 \text { patients had tumor progression treated with repeat surgery and/or } \\
\text { SRS/SRT. }\end{array}$} \\
\hline \multicolumn{6}{|c|}{$\begin{array}{l}\text { Of } 17 \text { operations for petroclival meningioma (in } 13 \text { patients), } 14 \text { were approached via the endonasal route for } \\
\text { conservative debulking and } 3 \text { via the retromastoid route; } 13 / 17(76 \%) \text { operations and } 9 / 13(69 \%) \text { patients had } \\
\text { meningiomas that extended into multiple compartments including CS, Meckel's cave, and/or sellar/suprasellar areas, } \\
8 / 13(61 \%) \text { had prior surgery and } 7(54 \%) \text { had prior radiation. }\end{array}$} \\
\hline
\end{tabular}




\section{Clinical outcomes and complications}

Major complications occurred in 23/193 (11.9\%) patients (Table 4). Permanent neurological worsening occurred in 12(6\%) patients including 4 with strokes and 8 with cranial nerve injuries (Supplemental Table 3). Reoperations were needed in 10(5\%) patients, (two for CSF leaks); 2(1\%) patients had meningitis No patients developed perioperative DVT, PE or MI. Three patients all with multiple prior surgeries, died of disease progression at 80, 229, and 3508 days after their last operation. 
Major and Minor Complications, Readmissions, Reoperations and Discharge Status in 193 Patients Undergoing 213 Keyhole Operations for Meningioma

\section{Major Surgical Complications ( $n=23$ patients)}

\section{Permanent Neurological Worsening}

- Stroke

- New or Worsening Cranial Nerve Dysfunction

Transient Neurological Worsening

- Persistent seizures with transient hemiparesis

\section{Reoperations}

- Delayed hematoma evacuation

- Reoperation for residual tumor (same admission)

- Reoperation for residual tumor (readmission)

- CSF leak repair

- Revision of sellar reconstruction (no CSF leak)

- Epistaxis needing surgical intervention

Meningitis

Total Major Complications by Operation $(p=0.45)$

- Redo-operation

- First-time operation

Minor Complications

- Sinusitis

- Mucocele

- Forehead numbness

- Frontalis paresis

- Frontalis palsy

- Delayed wound dehiscence

- Hardware malposition

Systemic Complications

- Aspiration Pneumonia

- UTI

- DVT/PE/ MI

Delayed Radiation Induced Optic Neuropathy
25

12 (6\%)

4 (2\%)

$8(4 \%)$

\section{$1(0.5 \%)$}

1

$10(5 \%)$

2

2

1

2

2

1

$2(1 \%)$

$7 / 47(15 \%)$

18/166 (11\%)

\section{3}

1

11

7

2

1

1

$2(1 \%)$

1

1

0

1

* One patient had both CSF leak and meningitis; one patient who had stroke had a multiply recurrent meningioma with prior surgery and RT and was the only mortality in the series 


\begin{tabular}{|ll|}
\hline Major Surgical Complications ( $\mathbf{n = 2 3}$ patients) & 25 \\
\hline Discharge to Home & $201 / 213(94 \%)$ \\
\hline Readmissions Requiring Surgical Intervention $(\mathbf{n = 4 / 2 1 3 )}$ & $2 \%$ \\
\hline - Residual tumor needing more surgery & 1 \\
\hline - Delayed hematoma needing surgery & 1 \\
\hline - CSF leak repair & 1 \\
\hline - Epistaxis & 1 \\
\hline Readmissions Managed Medically (n=2/213) & $1 \%$ \\
\hline - UTI, Atrial fibrillation & 1 \\
\hline - Hyponatremia & 1 \\
\hline $\begin{array}{l}\text { * One patient had both CSF leak and meningitis; one patient who had stroke had a multiply recurrent meningioma with } \\
\text { prior surgery and RT and was the only mortality in the series }\end{array}$ \\
\hline
\end{tabular}

\section{Discharge to home, functional outcomes and readmissions:}

Of 213 operations, 201(94\%) patients were discharged to home; 12(6\%) went to skilled nursing facility or rehabilitation (Table 5). Median LOS was higher for patients discharged to rehabilitation or skilled nursing facility versus home (5 vs 2 , p=0.012). Over 11 years, median LOS decreased: 3 days (first 71 cases), 3 days (middle 71 cases) and 2 days (last 71 cases), $p=0.013$. Longer LOS (LOS $\geq 4$ ) was associated with major complications $(22 \% \mathrm{vs} 7 \%, \mathrm{p}=0.005)$, discharge to rehabilitation or nursing facility $(67 \%$ vs. $28 \%, p=0.008)$. Ninety-day readmissions occurred in $6(2.8 \%)$ cases, including 4 who required surgery.

Of 184/193 (95\%) patients with available follow-up, favorable 90-day KPS was noted in 176(96\%): improved in $126 / 176(72 \%)$ and stable in 50/176 (28\%). Mean KPS for the entire cohort improved postoperatively from 72.3 to 82.4 $(p<0.001)$.

\section{SECONDARY OUTCOMES.}

Acute MRI changes in region of approach: Of 213 operations, POD 1 or 2 MRIs showed regional increase in FLAIR/T2 signal in 36(16.9\%), highest in the retromastoid cohort (37.5\%) (Table 2). FLAIR/T2 averaged $8 \pm 5 \mathrm{~mm}$ in maximal diameter and completely resolved in all but 11(5.2\%) cases on follow-up MRI. No patients with increased FLAIR had attributable neurological deficits to their FLAIR changes.

\section{Utility of endoscopy}

Endoscopy was used in 161(76\%) keyhole operations, including all 74 endonasal cases and 87/139(63\%) transcranial cases (Table 2). Of 87 endoscope-assisted transcranial cases, in $48(55 \%)$ it facilitated additional tumor removal.

\section{Long-term tumor progression or recurrence}

Mean follow-up for the 193 patients was $41 \pm 36$ months. Recurrence after GTR was seen in 1(1.2\%) patient, while progression of residual tumor occurred in $26(24.1 \%)$ patients, for an overall recurrence/progression rate of $13.9 \%$ (27/193). As per Kaplan-Meier analysis, mean time to recurrence or progression was $23.7 \pm 27.3$ months (range 3-94 
months). Of these 27 patients, 4 had repeat surgery only, 11 SRT only, 2 SRS followed by another surgery and 10 were observed or medically managed.

\section{Discussion}

\section{Minimally invasive philosophy applied to meningiomas}

MIS techniques aim to minimize collateral damage to normal tissues, maintain or improve quality of life, while achieving maximal tumor resection ${ }^{16-18,26,33,36}$. Striking that balance while being cost-effective is the ultimate "sweet spot" of any surgical procedure. We propose that the present series and prior series for intracranial meningioma are a step forward for neurosurgery and endoscopic skull base surgery, demonstrating the potential effectiveness of this paradigm $17,18,23,26,31,33,37$. This evolution is in part a result of cross-specialty collaboration. The adoption of the endoscope into transsphenoidal surgery that began in the 1990s with our colleagues in otorhinolaryngology, has transformed not only pituitary surgery but also the entire field of skull base surgery ${ }^{38}$. Most pituitary adenomas are now removed through an endoscopic endonasal approach, and as we show here, many midline skull base meningiomas can be removed via the endonasal route $32,39,40$.

Keyhole meningioma surgery aims to limit brain exposure and manipulation, accessing tumors through smaller strategically placed craniotomies without static brain retractors, facilitated by gravity-assistance, low profile instrumentation and endoscopy $17,18,33,41,42$. Despite the benefits of visualization, there is ample evidence that fixed brain retractors can cause acute and lasting brain injury ${ }^{41,43}$. Recent reports highlight the potential for retraction injury and associated complications with traditional craniotomies for tuberculum and planum meningiomas ${ }^{44-46}$. A major benefit of keyhole retractorless and gravity-assisted endoscopic approaches may be in less brain exposure and parenchymal manipulation $17,18,32,36,41,42,46$. This advantage was evidenced by the absence of early postoperative FLAIR/T2 changes along the surgical corridor in $82 \%$ of patients in this series including $100 \%$ of endonasal approaches; for 36 patients with FLAIR/T2 increases, these were small and resolved in all but $5 \%$ of patients.

For a neoplasm as diverse in location and invasiveness as meningioma, the surgical team should be facile working through multiple surgical corridors with both microscope and endoscope (see Table 1). Using TIVA anesthesia, smaller scalp and muscle incisions, minimal monopolar cautery, and focused craniotomies to minimize brain exposure, appears to promote rapid healing, less post-operative pain and a greater willingness and ability for patients to mobilize and leave the hospital ${ }^{30,31}$. Adoption of MIS techniques have been a key component of success in enhanced recovery protocols in other surgical subspecialties which we are adopting as well in all of our brain tumor patients ${ }^{31}$. Having reliable skull base closure techniques especially for endonasal, supraorbital and retromastoid routes where bony sinus and mastoid air cell entry frequently occurs is also essential to avoid CSF leaks and meningitis. This preventative strategy includes liberal use of abdominal fat grafts to obliterate sinus or air cell entry after craniotomy and a graded repair approach for skull base reconstruction including fat grafts and nasoseptal flaps in endonasal surgery without lumbar CSF drainage $29,34,47$.

To be valid, the MIS keyhole concept should yield low rates of new neurological deficits, CSF leaks and high rates of functional outcomes. Our results in terms of infrequent complications, short LOS and improved post-operative KPS scores support this approach. New cranial neuropathy was observed in only $4 \%$ of patients. Lumbar drains were used in only $3 \%$ of operations, while post-operative CSF leak rate and meningitis rates were only $1 \%$. There were no cases of perioperative DVT, PE, MI or 30-day mortality. The absence of thromboembolic events is likely due in part to our high patient functionality with few neurovascular complication, early ambulation and limited perioperative narcotic use, and compares favorably to the $2.7-4.1 \%$ incidence of PE/DVT recently published ${ }^{48}$. 
Prior studies and our experience demonstrate that complications impact quality of life, lengthen hospital stay, increase costs and often require reoperations and readmissions ${ }^{29,36,38-40}$. Compared to our outcomes of 3-day median LOS, 94\% discharged to home, and 7\% 90-day readmission rate, and no 30-day mortality, recent reports encompassing all intracranial meningiomas have documented LOS for skull base and other meningioma patients ranging from 4-11 days, discharge to home ranging from $70-83.4 \%, 90$-day readmission rates of $9.2-17.9 \%$, and 30-day mortality ranging from 0 $5.4 \% 49-53$. This comparison is notable, given our series is comprised predominantly (96\%) of skull base meningiomas (which are generally considered to be of higher complexity and risk profile than convexity meningiomas), while these 5 series include all intracranial meningiomas. A rapid complication-free recovery also benefits those patients who may have more aggressive (WHO Graded 2 or 3 ) or previously-treated meningiomas who may need to begin adjuvant therapy shortly after surgery ${ }^{35}$.

\section{Balancing goals of maximal tumor removal and complication avoidance}

Perhaps the most serious critique of keyhole meningioma surgery is that ultimately the patient is not well-served because overly conservative tumor removal leads to the eventual need for repeat surgery, radiosurgery, or possibly both. However, our overall meningioma resection rates for all locations except petroclival meningiomas are comparable to prior reports $^{10,13,44-46,51}$, and our progression/recurrence rate of $14 \%$ is similar to prior reports (almost all in patients who underwent NTR or STR), although this rate will undoubtedly increase with longer follow-up ${ }^{9,10,54-57}$. A growing collective experience places functional preservation as a higher priority than GTR resection, as highlighted by recent reports ${ }^{2,10,13,35}$. The beneficial impact of this approach for a given patient is a greater likelihood of no new postoperative neurological deficits and preserved or improved QOL while acknowledging that for many patients their meningioma becomes a chronic illness that warrants long-term monitoring with a higher likelihood of tumor progression and need for additional surgery, SRS/SRT or possible medical therapies in the years after non-GTR resection ${ }^{8-11,13,54-59}$.

Considering petroclival meningiomas, we did not achieve GTR in any of 17 operations and had one new CN deficit (6\%). In multiple series of petroclival meningiomas approached through traditional skull base approaches including the retromastoid approach, the GTR rate ranged from $21 \%-76 \%$ but permanent $\mathrm{CN}$ and other neurovascular complications ranged from $22 \%-54 \%^{2-5,60-63}$. Collectively, these reports indicate that overly aggressive attempts at GTR, will likely be associated with a relatively high rate of permanent neurovascular morbidity and lower quality of life for many patients; thus, we prefer a more conservative surgical approach for such invasive skull base meningiomas, as other groups have also recommended $10,11,13,37,54-59$.

\section{Study limitations and bias}

The major limitation of this study is its retrospective nature, and our selection bias for using these 6 keyhole approaches without a comparison cohort of patients treated with traditional skull base approaches, or other relatively new minimally invasive approaches such as the endoscopic transorbital route ${ }^{64,65}$. Also, the follow-up in our patients averaged 44 months which is relatively short. Longer follow-up is necessary to assess the efficacy of this approach more fully and determine how many patients who underwent NTR or STR ultimately need radiotherapy or additional surgery.

\section{Conclusions}

A minimally invasive keyhole paradigm applied to skull base and other select meningiomas can yield comparable tumor resection rates with low rates of neurovascular and systemic complications, short LOS and high rates of functional outcomes. While traditional skull base approaches remain valid and effective, we suggest that with increasing experience, transcranial and endonasal keyhole approaches can be considered part of the surgical armamentarium for many intracranial meningiomas.

Page $12 / 18$ 


\section{Declarations}

\section{ACKNOWELDGEMENTS}

The authors would like to acknowledge the support of Pacific Neuroscience Institute Foundation and Saint John's Health Center Foundation for their support. We would also like to acknowledge Josh Emerson for providing the artwork for Figures 2.

\section{COMPLIANCE WITH ETHICAL STANDARDS}

Funding: The authors did not receive support from any organization for the submitted work.

Conflict of Interest: DFK receives royalties from Mizuho Inc. GB is a consultant for Vascular Technologies Inc. and Cerevasc Inc. WS is a consultant for Stryker Corporation. JDT declares that he has no conflict of interest. RJM declares that he has no conflict of interest. AC declares that he has no conflict of interest. SY declares that she has no conflict of interest. AE declares that she has no conflict of interest. JR declares that he has no conflict of interest. HK declares that he has no conflict of interest. NM declares that he has no conflict of interest. CG declares that he has no conflict of interest.

Ethical approval: All procedures performed in studies involving human participants were in accordance with the ethical standards of the institutional and/or national research committee and with the 1964 Helsinki declaration and its later amendments or comparable ethical standards.

Informed consent: Informed consent was waived due to the retrospective nature of the study. For the patients discussed in the surgical videos, informed consent was obtained.

Data Availability: The datasets generated during and/or analyzed during the current study are available from the corresponding author on reasonable request.

Author Contributions: Study conception and design was performed by DFK, GB, JDT, and RJM. Material preparation, data collection and analysis were performed by JDT, RJM, AC, SY, AE, and JR. The first draft of the manuscript was written by JDT, DFK, and RJM and all authors commented on previous versions of the manuscript. All authors read and approved the final manuscript.

\section{References}

1. Ostrom QT, Patil N, Cioffi G, Waite K, Kruchko C, Barnholtz-Sloan JS (2020) CBTRUS statistical report: Primary brain and other central nervous system tumors diagnosed in the United States in 2013-2017. Neuro-oncology 22(Supplement1):iv1-iv96

2. Nanda A, Javalkar V, Banerjee AD (2011) Petroclival meningiomas: study on outcomes, complications and recurrence rates. Journal of neurosurgery 114(5):1268-1277

3. Couldwell WT, Fukushima T, Giannotta SL, Weiss MH (1996) Petroclival meningiomas: surgical experience in 109 cases. Journal of neurosurgery 84(1):20-28

4. Little KM, Friedman AH, Sampson JH, Wanibuchi M, Fukushima T (2005) Surgical management of petroclival meningiomas: defining resection goals based on risk of neurological morbidity and tumor recurrence rates in 137 patients. Neurosurgery 56(3):546-559

5. Isolan GR, Wayhs SY, Lepski GA, Dini LI, Lavinsky J (2018) Petroclival meningiomas: factors determining the choice of approach. Journal of neurological surgery Part B, Skull base 79(4):367

6. Faramand A, Kano H, Niranjan A, Park K-J, Flickinger JC, Lunsford LD (2019) Tumor control and cranial nerve outcomes after adjuvant radiosurgery for low-grade skull base meningiomas. World neurosurgery 127:e221-e229 
7. Pollock BE, Stafford SL, Link MJ, Garces YI, Foote RL (2013) Single-fraction radiosurgery of benign cavernous sinus meningiomas. Journal of neurosurgery 119(3):675-682

8. Bunevicius A, Pikis S, Anand RK et al (2021) Stereotactic radiosurgery for clinoid meningiomas: a multi-institutional study. Acta Neurochirurgica 163(10):2861-2869

9. Przybylowski CJ, Raper DM, Starke RM, Xu Z, Liu KC, Sheehan JP (2015) Stereotactic radiosurgery of meningiomas following resection: predictors of progression. Journal of Clinical Neuroscience 22(1):161-165

10. Gozal YM, Alzhrani G, Abou-Al-Shaar H, Azab MA, Walsh MT, Couldwell WT (2019) Outcomes of decompressive surgery for cavernous sinus meningiomas: long-term follow-up in 50 patients. Journal of neurosurgery 132(2):380387

11. Gousias K, Schramm J, Simon M (2016) The Simpson grading revisited: aggressive surgery and its place in modern meningioma management. Journal of neurosurgery 125(3):551-560

12. Sughrue ME, Kane AJ, Shangari G et al (2010) The relevance of Simpson Grade I and II resection in modern neurosurgical treatment of World Health Organization Grade I meningiomas. Journal of neurosurgery 113(5):10291035

13. Beer-Furlan A, Priddy BH, Jamshidi AO et al (2020) Improving Function in Cavernous Sinus Meningiomas: A Modern Treatment Algorithm. Frontiers in Neurology 11:652

14. Tsui C, Klein R, Garabrant M (2013) Minimally invasive surgery: national trends in adoption and future directions for hospital strategy. Surgical endoscopy 27(7):2253-2257

15. Smith ZA, Fessler RG (2012) Paradigm changes in spine surgery-evolution of minimally invasive techniques. Nature Reviews Neurology 8(8):443-450

16. Wilson DH (1971) Limited exposure in cerebral surgery. Journal of neurosurgery 34(1):102-106

17. Reisch R, Stadie A, Kockro RA, Hopf N (2013) The keyhole concept in neurosurgery. World neurosurgery $79(2): S 17$. e19-S17. e13.

18. Lan Q, Sughrue M, Hopf NJ et al (2019) International expert consensus statement about methods and indications for keyhole microneurosurgery from International Society on Minimally Invasive Neurosurgery.Neurosurgical review:117

19. Gardner PA, Kassam AB, Thomas A et al (2008) Endoscopic endonasal resection of anterior cranial base meningiomas. Neurosurgery 63(1):36-54

20. Cavallo LM, Messina A, Cappabianca P et al (2005) Endoscopic endonasal surgery of the midline skull base: anatomical study and clinical considerations. Neurosurg Focus 19(1):1-14

21. Dusick JR, Esposito F, Kelly DF et al (2005) The extended direct endonasal transsphenoidal approach for nonadenomatous suprasellar tumors. Journal of neurosurgery 102(5):832-841

22. Laws ER, Kanter AS, Jane JA, Dumont AS (2005) Extended transsphenoidal approach. Journal of neurosurgery 102(5):825-828

23. Todeschini AB, Beer-Furlan A, Otto B, Prevedello DM, Carrau RL (2020) Endoscopic endonasal approaches for anterior skull base meningiomas. Anterior Skull Base Tumors 84:114-123

24. Barkhoudarian G, Farahmand D, Louis RG et al (2017) Microsurgical endoscope-assisted gravity-aided transfalcine approach for contralateral metastatic deep medial cortical tumors. Operative Neurosurgery 13(6):724-731

25. Villanueva P, Louis RG, Cutler AR et al (2015) Endoscopic and gravity-assisted resection of medial temporo-occipital lesions through a supracerebellar transtentorial approach: technical notes with case illustrations. Operative Neurosurgery 11(4):475-483

26. Thakur JD, Mallari RJ, Corlin A et al (2020) Minimally invasive surgical treatment of intracranial meningiomas in elderly patients ( $\geq 65$ years): outcomes, readmissions, and tumor control. Neurosurg Focus 49(4):E17 
27. Fatemi N, Dusick JR, de Paiva Neto MA, Malkasian D, Kelly DF (2009) Endonasal versus supraorbital keyhole removal of craniopharyngiomas and tuberculum sellae meningiomas. Operative Neurosurgery 64(suppl5):ons269-ons287

28. Sivakumar W, Barkhoudarian G, Lobo BM et al (2019) Strategy and Technique of Endonasal Endoscopic Bony Decompression and Selective Tumor Removal in Symptomatic Skull Base Meningiomas of the Cavernous Sinus and Meckel's Cave. World neurosurgery 131:e12-e22

29. Conger A, Zhao F, Wang $X$ et al (2018) Evolution of the graded repair of CSF leaks and skull base defects in endonasal endoscopic tumor surgery: trends in repair failure and meningitis rates in 509 patients. Journal of neurosurgery 130(3):861-875

30. Avery MB, Mallari RJ, Barkhoudarian G, Kelly DF (2021) Supraorbital and mini-pterional keyhole craniotomies for brain tumors: a clinical and anatomical comparison of indications and outcomes in 204 cases. Journal of neurosurgery.

31. Mallari RJ, Avery MB, Corlin A et al (2021) Streamlining brain tumor surgery care during the COVID-19 pandemic: A case-control study. Plos one 16(7):e0254958

32. Mallari RJ, Thakur JD, Rhee JH et al (2021) Endoscopic Endonasal and Supraorbital Removal of Tuberculum Sellae Meningiomas: Anatomic Guides and Operative Nuances for Keyhole Approach Selection.Operative Neurosurgery.

33. Burks JD, Conner AK, Bonney PA et al (2016) Management of intracranial meningiomas using keyhole techniques.Cureus.; 8(4)

34. Ansari SF, Eisenberg A, Rodriguez A, Barkhoudarian G, Kelly DF (2020) The supraorbital eyebrow craniotomy for intraand extra-axial brain tumors: a single-center series and technique modification. Operative Neurosurgery 19(6):667677

35. Schwartz TH, McDermott MW (2020) The Simpson grade: abandon the scale but preserve the message. Journal of Neurosurgery 1(aop):1-8

36. Teo C (2010) The concept of minimally invasive neurosurgery. Neurosurgery Clinics of North America 21(4):583-584

37. Beer-Furlan A, Abi-Hachem R, Jamshidi AO, Carrau RL, Prevedello DM (2016) Endoscopic trans-sphenoidal surgery for petroclival and clival meningiomas. Journal of Neurosurgical sciences 60(4):495-502

38. Wang EW, Zanation AM, Gardner PA et al (2019) ICAR: endoscopic skull-base surgery. Paper presented at: International forum of allergy \& rhinology

39. Asemota AO, Ishii M, Brem H, Gallia GL (2017) Comparison of complications, trends, and costs in endoscopic vs microscopic pituitary surgery: analysis from a US health claims database. Neurosurgery 81(3):458-472

40. Koutourousiou M, Fernandez-Miranda JC, Stefko ST, Wang EW, Snyderman CH, Gardner PA (2014) Endoscopic endonasal surgery for suprasellar meningiomas: experience with 75 patients. Journal of neurosurgery 120(6):13261339

41. Spetzler RF, Sanai N (2012) The quiet revolution: retractorless surgery for complex vascular and skull base lesions. Journal of neurosurgery 116(2):291-300

42. Kalani MYS (2020) Prospective Evaluation of the Need for Fixed Brain Retractors During Complex Cranial Surgery. World neurosurgery 139:e61-e69

43. Rosenørn J, Diemer N (1985) The risk of cerebral damage during graded brain retractor pressure in the rat. Journal of neurosurgery 63(4):608-611

44. Makarenko S, Carreras EM, Akagami R (2017) Craniotomy for perisellar meningiomas: comparison of simple (appropriate for endoscopic approach) versus complex anatomy and surgical outcomes. Journal of neurosurgery 126(4):1191-1200

45. Kong D-S, Hong C-K, Hong SD et al (2018) Selection of endoscopic or transcranial surgery for tuberculum sellae meningiomas according to specific anatomical features: a retrospective multicenter analysis (KOSEN-002). Journal

Page 15/18 
of neurosurgery 130(3):838-847

46. Bander ED, Singh H, Ogilvie CB et al (2017) Endoscopic endonasal versus transcranial approach to tuberculum sellae and planum sphenoidale meningiomas in a similar cohort of patients. Journal of Neurosurgery 128(1):40-48

47. Taha ANM, Almefty R, Pravdenkova S, Al-Mefty O (2011) Sequelae of autologous fat graft used for reconstruction in skull base surgery. World neurosurgery 75(5-6):692-695

48. Fluss R, Kobets AJ, Inocencio JF et al (2021) The incidence of venous thromboembolism following surgical resection of intracranial and intraspinal meningioma. A systematic review and retrospective study.Clinical Neurology and Neurosurgery::106460

49. Sharma M, Ugiliweneza B, Boakye M, Andaluz N, Williams BJ (2019) Feasibility of bundled payments in anterior, middle, and posterior cranial fossa skull base meningioma surgery: MarketScan analysis of health care utilization and outcomes. World neurosurgery 131:e116-e127

50. Abou-Al-Shaar H, Azab MA, Karsy M, Guan J, Couldwell WT, Jensen RL (2018) Assessment of costs in open microsurgery and stereotactic radiosurgery for intracranial meningiomas. World neurosurgery 119:e357-e365

51. Ehresman JS, Garzon-Muvdi T, Davis Rogers ML et al (2019) Risk of developing postoperative deficits based on tumor location after surgical resection of an intracranial meningioma. Journal of neurological surgery Part B, Skull base 80(1):59

52. James Z, Leach PA, Hayhurst C (2019) Is 30-day readmission an accurate measure of morbidity in cranial meningioma surgery? British journal of neurosurgery 33(4):379-382

53. McKee SP, Yang A, Gray M et al (2018) Intracranial meningioma surgery: value-based care determinants in New York state, 1995-2015. World neurosurgery 118:e731-e744

54. De Jesús O, Sekhar LN, Parikh HK, Wright DC, Wagner DP (1996) Long-term follow-up of patients with meningiomas involving the cavernous sinus: recurrence, progression, and quality of life. Neurosurgery 39(5):915-920

55. Heald JB, Carroll TA, Mair RJ (2014) Simpson grade: an opportunity to reassess the need for complete resection of meningiomas. Acta neurochirurgica 156(2):383-388

56. Savardekar AR, Patra DP, Bir S et al (2018) Differential Tumor Progression Patterns in Skull Base Versus Non-Skull Base Meningiomas: A Critical Analysis from a Long-Term Follow-Up Study and Review of Literature. World neurosurgery 112:e74-e83

57. Oya S, Ikawa F, Ichihara N et al (2021) Effect of adjuvant radiotherapy after subtotal resection for WHO grade I meningioma: a propensity score matching analysis of the Brain Tumor Registry of Japan. Journal of Neuro-Oncology 153(2):351-360

58. Brokinkel B, Stummer W, Sporns P (2018) Simpson grade IV resections of skull base meningiomas: does the postoperative tumor volume impact progression? Journal of neuro-oncology 137(1):219-221

59. Nanda A, Bir SC, Maiti TK, Konar SK, Missios S, Guthikonda B (2017) Relevance of Simpson grading system and recurrence-free survival after surgery for World Health Organization Grade I meningioma. Journal of neurosurgery 126(1):201-211

60. Natarajan SK, Sekhar LN, Schessel D, Morita A (2007) Petroclival meningiomas: multimodality treatment and outcomes at long-term follow-up. Neurosurgery 60(6):965-981

61. Almefty R, Dunn IF, Pravdenkova S, Abolfotoh M, Al-Mefty O (2014) True petroclival meningiomas: results of surgical management. Journal of neurosurgery 120(1):40-51

62. Li D, Hao S-Y, Wang L et al (2013) Surgical management and outcomes of petroclival meningiomas: a single-center case series of 259 patients. Acta neurochirurgica 155(8):1367-1383

63. Mathiesen T, Gerlich Ã, Kihlström L, Svensson M, Bagger-Sjöbäck D (2007) Effects of using combined transpetrosal surgical approaches to treat petroclival meningiomas. Neurosurgery 60(6):982-992

Page 16/18 
64. Dallan I, Sellari-Franceschini S, Turri-Zanoni M et al (2018) Endoscopic transorbital superior eyelid approach for the management of selected spheno-orbital meningiomas: preliminary experience. Operative Neurosurgery 14(3):243251

65. Kong D-S, Kim YH, Hong C-K (2020) Optimal indications and limitations of endoscopic transorbital superior eyelid surgery for spheno-orbital meningiomas. Journal of Neurosurgery 134(5):1472-1479

\section{Figures}
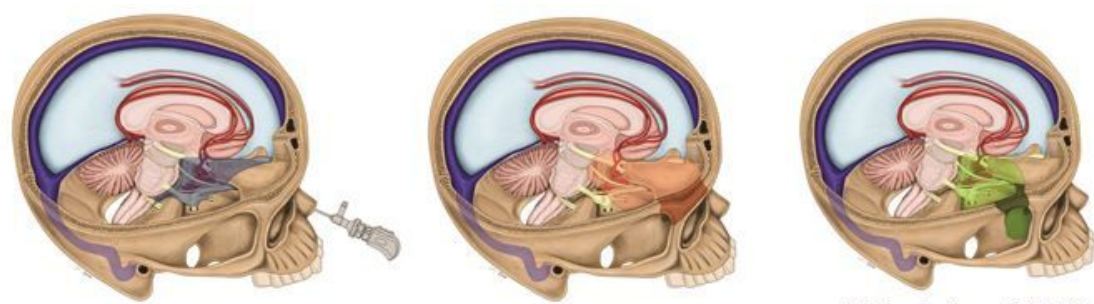

Endonasal $\mathrm{N}=\mathbf{7 4}$
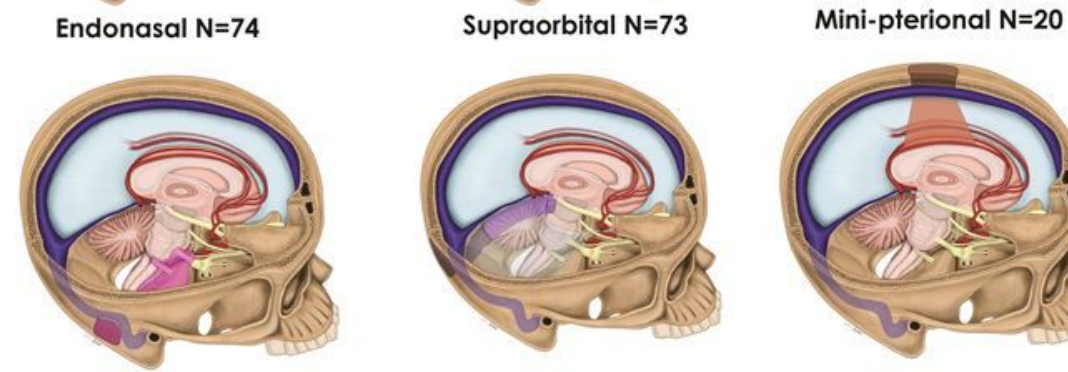

Supracerebellar $\mathrm{N}=4$

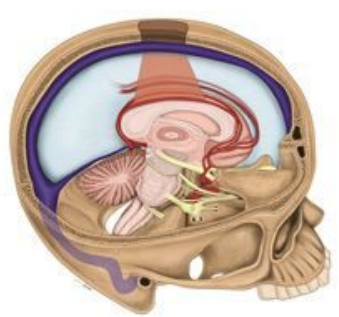

Transfalcine $\mathrm{N}=4$

Retromastoid $\mathrm{N}=38$

A

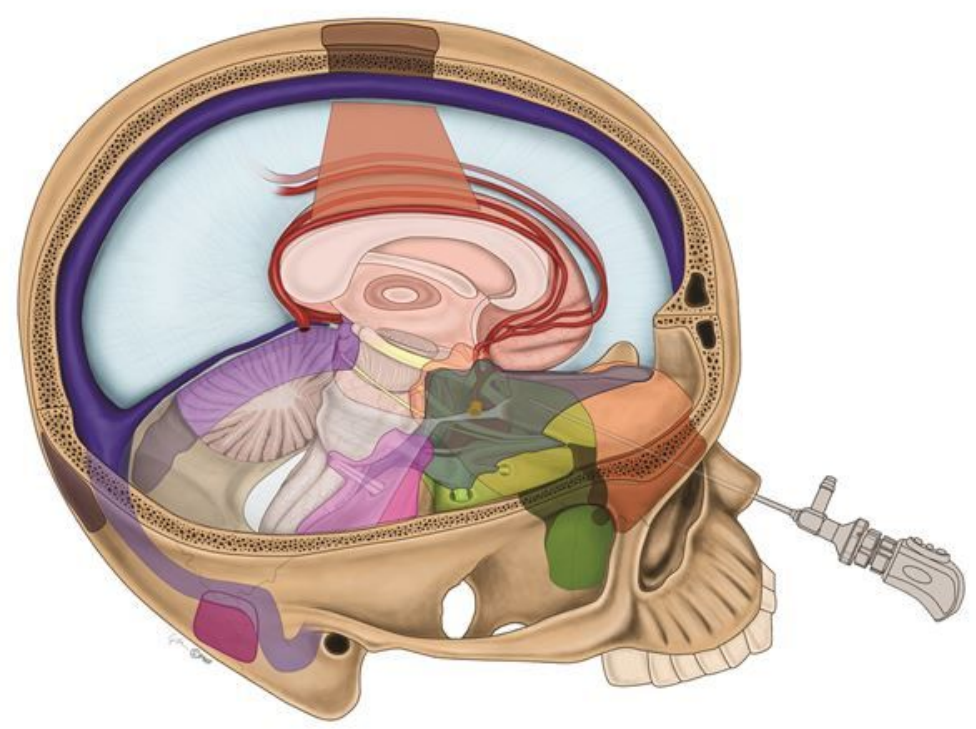

B

\section{Figure 1}

(1A,1B): Drawing and GIF animation (Supplemental File) depicting 6 keyhole approaches for meningioma removal: 1) endonasal, 2) supraorbital, 3) minipterional, 4) retromastoid, 5) suboccipital sitting gravity-assisted and 6) transfalcine gravity-assisted. 


\section{Supplementary Files}

This is a list of supplementary files associated with this preprint. Click to download.

- SupplementalTables.docx

- KeyholeMeningiomaSupplementalFigureGIF.gif

- KeyholeMeningiomaVideo1.docx

- KeyholeMeningiomaVideo2.docx 